\section{EMBRYRIDDLE}

Aeronautical University

SCHOLARLY COMMONS
Journal of Aviation/Aerospace

Education \& Research

Volume 29

Number 1 JAAER 2020

Article 1

2020

\title{
Scenario-Based Strategic Planning for Future Civil Vertical Take- off and Landing (VTOL) Transport
}

WooJin Choi

Embry-Riddle Aeronautical University, choiw1@my.erau.edu

Steven Hampton

Embry-Riddle Aeronautical University, hamptons@erau.edu

Follow this and additional works at: https://commons.erau.edu/jaaer

Part of the Management and Operations Commons, Technology and Innovation Commons, Transportation Engineering Commons, and the Urban, Community and Regional Planning Commons

\section{Scholarly Commons Citation}

Choi, W., \& Hampton, S. (2020). Scenario-Based Strategic Planning for Future Civil Vertical Take-off and Landing (VTOL) Transport. Journal of Aviation/Aerospace Education \& Research, 29(1). https://doi.org/ 10.15394/jaaer.2020.1808

This Article is brought to you for free and open access by the Journals at Scholarly Commons. It has been accepted for inclusion in Journal of Aviation/Aerospace Education \& Research by an authorized administrator of Scholarly Commons. For more information, please contact commons@erau.edu. 


\section{Introduction}

\section{Background of the Study}

Over the last four decades, vertical take-off and landing (VTOL) aircraft have been deployed mainly for military operations in areas where longer flight than a helicopter and landing in a vertical flight configuration are required. On the other hand, little contribution has been made to the civil aviation sector mainly because of the limited payload capacity, inefficient fuel consumption, and high level of cabin noise.

However, the vertical flight ability without the need for a runway and the speed, flight range and flight performance equivalent to a turboprop of the VTOL technology have been perceived as an attractive remedy to relieve increasing airport and airspace congestion in the metropolitan areas (Chung et al., 2011). Recent technical advancement of hybrid-electric propulsion, which combines batteries with turbine engines with higher efficiency and lower emissions, can help enable regional airline service to remote communities using the potential VTOL transports (Warwick, 2014).

In addition, VTOL technology is also expected to have a large impact on the future intraand intercity transport systems by providing "on demand" mobility within 50-500 miles (Moore \& Goodrich, 2013) and improve connectivity between airports and population centers in the metropolitan areas, which would strengthen competitiveness of the air transport mode over other ground transport systems such as high-speed rail and highway.

As a recent movement, the Italian AW609 business tiltrotor VTOL program inspired by the military V-22 Osprey aircraft is underway as the first civil VTOL aircraft in the world and certification of the aircraft is projected to occur in 2020 (Perry, 2016). Its recent flight test results in 2015 revealed significant improvement of payload and flight range: a maximum take- 
off weight up to 18,000 pounds and a standard maximum range up to 1,100 nautical miles with cruise speed at 275 knots at 25,000 feet (Clarke, 2015).

Furthermore, recent studies conducted by NASA, Boeing, and Airbus on hybrid-electric powered VTOL propulsion technology have demonstrated the feasibility of a category of 90-120 seated civil VTOL aircraft, which is expected to bring a significant impact on the current commercial aviation system (Chung et al., 2011; Ozdemir et al., 2014; Warwick, 2014).

\section{Current Problem of Airport Infrastructure}

When considering continuous increase of the air traffic volume both for passenger and air cargo and rapidly evolving technologies, it is of great importance that airports are able to maintain flexible responding systems to the changing air travel demand and dynamic industrial environment that may affect overall airport operations (Fife \& McNerney, 2000). However, in many metropolitan areas, limited airport and airspace capacity have resulted in delays which are primarily caused by bottlenecks during final approach, the turnaround process, and take-off procedures and required capacity expansion of the airfield system (Xue, 2006).

Expanding the capacity of existing airport infrastructure, specifically in the airside area, is usually constrained by community agreements on environmental issues such as noise and air pollution and land availability. Developing or relocating major airports on green-field sites within a reasonable distance from population centers is also a difficult option to undertake because it will require extensive investments in land preparation and development of access infrastructure to the population centers. In the end, the capacity development costs are imposed on related stakeholders such as government, airlines, and passengers (Organisation for Economic Co-operation and Development [OECD], 2014).

In 2016, Airport Council International (ACI) published an annual traffic report and 
attributed increasing airport congestions primarily to over-capacity of airports by demonstrating that 45 of the 100 busiest airports in the world by passenger volume exceeded current runway or terminal facility design capacity. According to delay analysis by the Eurocontrol (2017), 36\% of flights in 2013 were reportedly delayed by more than five minutes in Europe, and the Federal Aviation Administration (FAA) reported that $31.1 \%$ of flights in the United States experienced delays by more than 15 minutes (Sternberg et al., 2017). In the U.S., despite the expected benefits from the NextGen system such as throughput increase and more efficient routes management, the FAA identified that under the steady traffic growth as forecasted, delays will continue to grow at 12 major airports in the U.S. (FAA, 2015).

Without effective resolutions such as new or reconfigured runways, congestion at major airports is expected to cause more and more delays in travel time and unnecessary costs for both airlines and passengers. In this context, in the last decade, technical advancement with the potential civil VTOL transport has gained significant interest both in research and investment due to the multiple socio-economic factors, such as massive fuel costs, noise reduction, and user benefits in the air transportation industry (Kasliwal et al., 2019).

\section{Purpose of the Study and Delimitations}

With the nature of non-interference operations (NIO) and runway-independent operations (RIO) of short-haul traffic (Chung et al., 2011), the civil VTOL transport mode has a potential to contribute a broad spectrum of the current air transport system. While the purpose of this study was to add to the knowledge of the VTOL technology as a mass transit system and its potential benefits to reduce airport congestions, improve operation efficiency, and enhance competitiveness of the air transport industry, it is also worth including certain consideration for 
autonomous 'flying cars' or 'air taxi' type of vehicles using the VTOL technology as this will affect the future airspace system.

Accordingly, it aimed to envision a plausible scenario of an integrative development of a broad range of civil VTOL aircraft within the existing air transport system for a 20+-year timeline and propose a strategic development framework.

\section{Literature Review}

An extensive review of the literature and industrial reports regarding civil VTOL aircraft was conducted with three major focuses: technology advancement, infrastructure requirements, and integrative operation of VTOL into the conventional air transport network. While a large volume of previous research can be found in the context of VTOL propulsion technology, the extent of the previous studies in conjunction with a systematic approach concerning VTOL aircraft and conventional air transport system compatibility is identified to be scarce.

\section{Civil VTOL Technology}

It was the 1920s and 1930s when numerous innovative flying concepts and designs were invented inclusive of vertical take-off and landing vehicles. In the United States, Henry Berliner introduced a design resembled a fixed-wing biplane in the early 1920s that equips propellers mounted on a tip of each wing which would be tilted forward for forward flight. Meanwhile, George Lehberger was issued a patent in 1930 for a design that provides vertical lift and forward flight taking a basic concept of the tilt rotor aircraft. These schemes can be regarded as primitive forms of tilting-propulsion VTOL aircraft. Later, the XV-3 had been built in 1953 as an experimental aircraft to prove the soundness of the tilt-rotor aircraft and gathered necessary data needed for future tilt-rotor VTOL designs, which resulted in the XV-15 tilt-rotor research aircraft 
in 1972. Using the experience gained from the XV-3 and XV-15, Bell Helicopter Textron and Boeing Helicopters developed the V-22 Osprey in 1981 (Zhou, Zhao, \& Liu, 2020).

Since then, research in speed and payload of civil VTOL aircraft with a hybrid-electric propulsion system has been initiated and spurred on by NASA. With a focus on the integration of the VTOL technology into commercial aviation, NASA has studied the technical and economic viability of VTOL aircraft since the late 1970s (Albers \& Zuk, 1987). Through a series of research projects, NASA has enhanced propulsion power as well as reduced noise levels of the VTOL aircraft, as described in Table 1. The NASA's latest Large Civil Tiltrotor $\left(2^{\text {nd }}\right.$ generation, or LCTR2) vehicle was designed to carry 90 passengers at 300 knots with a 1,000 nautical mile and necessitates only helipads within airport boundaries. Its goal and operational scheme are to remove short- and medium-range air traffic from runways and free up the runways for larger and longer-range aircraft. In other studies, NASA has demonstrated the technical feasibility of increased payload capacity of 90-120 passengers with the tiltrotor type VTOL aircraft (Wood, 2012). With this achievement, the VTOL flight is likely to explore technical and commercial viability within current commercial air transport, which will necessitate compatibility with the national airspace system (Chung et al., 2011).

More interest in hybrid-electric propulsion has recently been spurred by works conducted by Boeing for NASA. The Subsonic Ultra Green Aircraft Research study, completed in 2010, anticipated technologies for a B737-class VTOL aircraft to enter services in 2030-35 that could meet aggressive targets for propulsion, emissions and noise reduction (Warwick, 2014).

In Europe, Airbus Innovations Group and Rolls-Royce are studying distributed electric propulsion for airliners, focusing initially on a 100-passenger, 2,000-nautical mile range and a Mach 0.75-cruise concept that could enter service in the mid-2030s. As a next step, Airbus and 
Rolls-Royce are proposing flight tests in 2022 of electrically driven auxiliary fans for drag reduction on a 100-seater under Europe's Clean Sky 2 research program (Warwick, 2014).

Table 1

Major Studies led by NASA on a Civil VTOL Model

\begin{tabular}{|c|c|c|c|}
\hline Timeline & Research Topics & VTOL Capacity & Participants \\
\hline $1987-1991$ & $\begin{array}{l}\text { Civil Tiltrotor Missions } \\
\text { and Applications }\end{array}$ & $\begin{array}{l}\cdot 8-75 \mathrm{pax} \\
\cdot 270-300 \mathrm{kts}\end{array}$ & $\begin{array}{l}\text { NASA, } \\
\text { Boeing, Bell }\end{array}$ \\
\hline $1993-2001$ & $\begin{array}{l}\text { Short-Haul Civil } \\
\text { Tiltrotor Concepts }\end{array}$ & $\begin{array}{l}\text { - } 40 \mathrm{pax} \\
\text { - } 315 \mathrm{kts}\end{array}$ & NASA \\
\hline $2000-2005$ & $\begin{array}{l}\text { Runway Independent } \\
\text { Aircraft Studies, Heavy-Lift Rotorcraft } \\
\text { Systems Investigation }\end{array}$ & $\begin{array}{l}\text { - } 120 \mathrm{pax} \\
\text { - } 350 \mathrm{kts}\end{array}$ & NASA \\
\hline $2009-2013$ & $\begin{array}{l}\text { Modeling High Speed } \\
\text { Civil VTOL Transports in the Next } \\
\text { Generation Airspace, Advanced Vehicle } \\
\text { Concepts and Implications for NextGen }\end{array}$ & $\begin{array}{l}\cdot 30-120 \mathrm{pax} \\
\cdot 250-350 \mathrm{kts}\end{array}$ & $\begin{array}{l}\text { NASA, } \\
\text { SAIC, } \\
\text { Sensis, } \\
\text { Boeing }\end{array}$ \\
\hline
\end{tabular}

Note: Data from “NASA Vertical Lift Strategy Direction,” by S. A. Gorton, 2016.

In 2016, the Defense Advanced Research Projects Agency (DARPA), the Pentagon's research department, contracted the Phase 2 contract for the VTOL X-Plane project with Aurora Flight Sciences with the goal of enhancement of VTOL technology to reach cruising speeds between 345 and $460 \mathrm{mph}$ while carrying approximately 12,000 pounds (Goncalves, 2016).

In 2016, Boeing was awarded a patent for a tilt-rotor VTOL aircraft capable of carrying up to 100 passengers. The patent describes the aircraft configuration for both military and personal use. If this patent is slated for production, it could be a competitive mode of transportation as a regional passenger aircraft.

Because VTOL aircraft are an energy-intensive transportation mode for short distances, higher propulsion, and high-capacity battery technology was identified as two critical enablers to overcome current challenges with civil VTOL aircraft (German et al., 2013; Sinsay et al., 2012; 
Warwick, 2014). In consideration of current technological trend, the electric powered VTOL aircraft designs were foreseen to be available by 2030 (Young et al., 2011; Wang, Hou, Guo, \& Gao, 2015).

\section{Infrastructure for Civil VTOL: Vertiport}

Given the extensive investment and resources to build new airports or runways, airport operators have been intrigued to increase the capacity of existing airports by maximizing the airfield efficiency or optimizing aircraft turn-around process. As a result, several meaningful studies have been conducted to determine whether and how VTOL aircraft and vertiports at airports could improve the throughput of national air transportation system (Lindsey et al., 2012; Patterson et al., 2013).

In the FAA's Advisory Circular (AC150/5390-3, 1991), the term 'Vertiport' is defined as “an identifiable ground or elevated area, including any buildings or facilities thereon, used for the takeoff and landing of tiltrotor aircraft and rotorcraft" (p. 1). In the subsequent advisory circular, the FAA and the U.S. Department of Transportation (DoT) jointly published planning and design guidelines for vertiports (Peisen \& Ferguson, 1996). In this paper, actual designs of five vertiports at specific sites were proposed and an on-airport vertiport at John F. Kennedy International Airport (JFK) demonstrated that the experience gained in airport design could make future vertiport designs possible.

Xue (2006) built the models and methods required to effectively integrate runwayindependent aircraft traffic into terminal-area airspace without impacting existing traffic queues, which was accomplished through the design of simultaneous non-interfering terminal area trajectories that minimize ground noise exposure. Young and Rajagopalan (2013) simulated the impact of tiltrotor wake interactions from civil VTOL aircraft operations near terminal buildings. 
In 2015, the Vertiport Chicago, sited in 10-acre layout, commenced its commercial operations and has represented the viable alternative for helicopters, police and fire department aircraft, executive charters, and potential VTOL aircraft, which is expected to help relieve OHare and Midway airports' increasing congestions.

\section{Integration of Civil VTOL into a Metropolitan or Regional Transportation System}

While previous studies have shown that VTOL has the potential to improve airspace performance in capacity and delay based on an integrated fleet concept of operations, integrating VTOL aircraft into conventional airspace will be a complex issue. The study on VTOL mass transit feasibility jointly studied by NASA and Stanford (Sinsay et al., 2012) presented a conceptual design of an electric VTOL public transit system and network models using the existing railways and bus networks in the San Francisco metropolitan area. The simulations of a 30 seater VTOL operations carrying up to 30,000 passengers a day connecting eight potential multi-modal vertiports at population centers, with existing infrastructure of three airports, roads and rail links in the metropolitan area demonstrated the inevitable airspace management issues.

In 2011, Chung et al. verified expected airspace performance benefits gained by NIO and RIO operations with four possible scenario models of 1) connecting congested hubs, 2) connecting a feeder and a hub, 3) services to population centers, and 4) services to remote locations, and identified potential issues for integrating civil VTOL transport into the existing airspace. As a result, requirements for compatible operations within the national airspace system and the future NextGen applications were proposed.

Warwick (2014) conducted simulations which indicated that a dynamic flightpath routing could reduce potential conflicts with the air traffic and limit controller workload by avoiding 
heavily used airspace. Also, the result suggested that enabling a VTOL-style public transport network would require a high level of automation on the ground and in the air (Warwick, 2014). Mueller, Kopardekar, and Goodrich (2017) attempted to lay out a vision for a new air transportation system built on the principles of on-demand air mobility by leveraging the precedent for VFR operations and employing UAS traffic management system technologies, concepts, procedures, and capabilities that are or could soon be available.

\section{Methodology}

In this study, four major methodologies were adapted to create a strategic scenario plan.

\section{Assess Demand and Driving Forces with a Value Proposition Mapping}

The major trends in the aviation industry that will necessitate the civil VTOL flight were foreseen to determine how the VTOL technology may help relieve current industrial problems and satisfy the socio-economic demands.

\section{Evaluate Critical Challenges and Uncertainties with a PESTEL Analysis}

The critical challenges and uncertainties, which would disturb the driving forces to realize the VTOL technology into real-world, were identified in terms of politics, economics, sociology, technology, and legal (PASTEL) perspectives and counter-measures were proposed.

\section{Identify Plausible Scenarios with a Technology Readiness Level (TRL)}

The identified driving forces and critical challenges were combined and compared to current technology readiness level to draw plausible scenarios.

\section{Define the Practical Implementation Plan with a Scenario Assessment Matrix}

Lastly, the implications and potential impacts of the selected scenario were assessed using the Option Matrix Tool (OMT) (Enz \& Thompson, 2013) so that high-level goals and implementation plans were presented. 
As shown in Figure 1, this process began with an extensive review of the literature focusing on the current VTOL technology, infrastructure, and integration of the technology into the existing transportation system. Based on the information gathered, strategic needs of a civil VTOL transport mode and external challenges were reviewed. In consideration of the expected future state of a civil VTOL system, three distinct scenarios that are likely to happen were identified and assessed to determine an integration model with the existing air transport system. After the most feasible scenario was selected through a weighted point evaluation process, focusing on the selected scenario, a strategic development plan along with key milestones for the next 20 years was proposed.

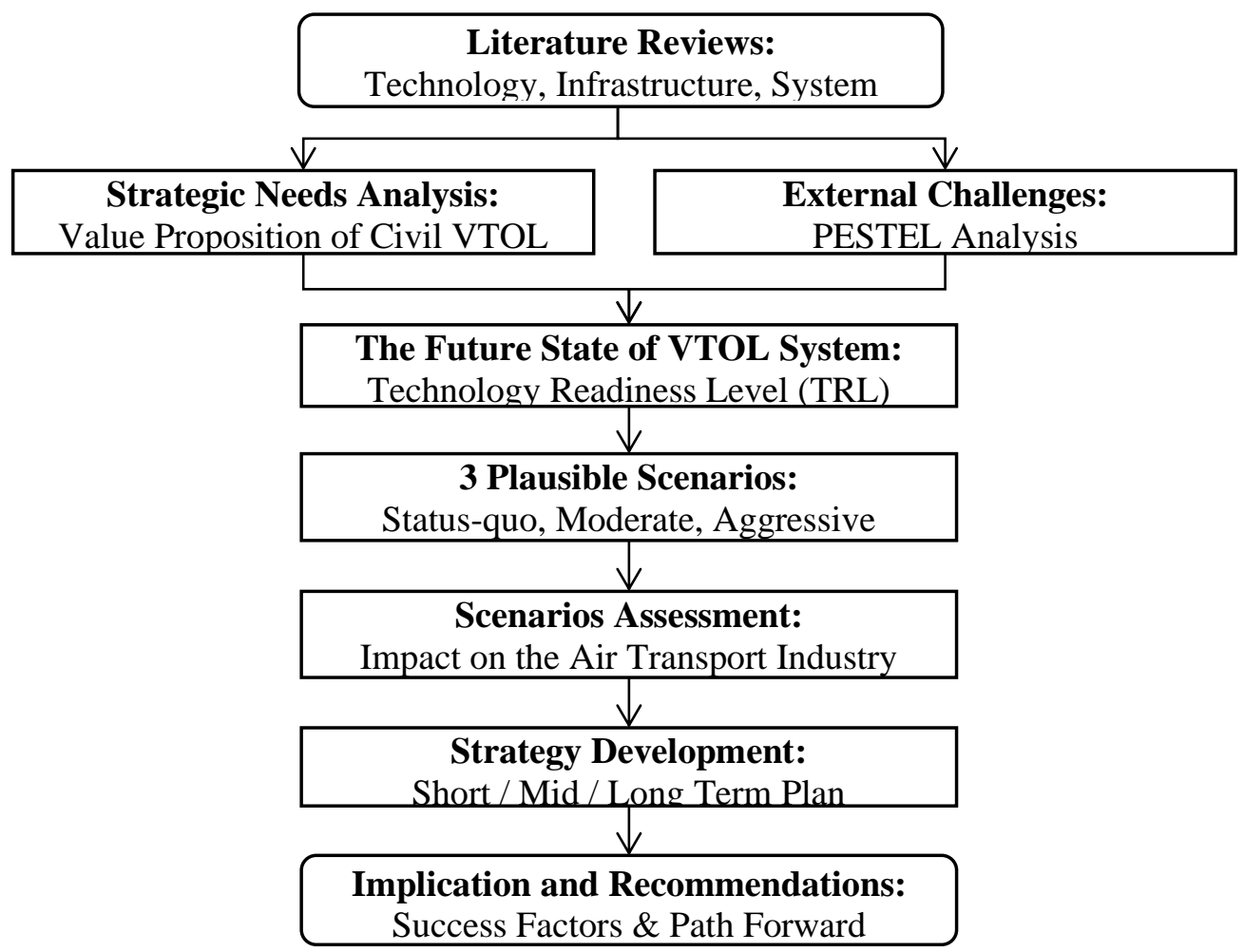

Figure 1. The scenario-based strategic planning process to develop a feasible civil VTOL transport mode. 


\section{Strategic Needs and Challenges}

\section{Needs Analysis and Value Proposition of the Civil VTOL Transport Mode}

To satisfy today's evolving complex needs of diversified stakeholders in the aviation industry, it is essential to have an industry-wide perspective encompassing entire related segments from regulatory frameworks, aircraft, infrastructure to operating procedures for the deployment of the new technology in the air transport industry. With the continuous growth of metropolitan areas and increasing levels of congestion and cost profile of the current airspace, airport, and ground transportation systems, integration of the future civil VTOL and the conventional aircraft system would help address these issues. The value proposition and potential benefits of VTOL technology to society was contemplated as below.

Travel time. The travel and transit time between airports and passengers' destination can be reduced with the support of civil VTOL flights by avoiding ground transportation time to population centers.

Infrastructure efficiency. Congestions and environmental impact such as noise and pollution both from airport and ground access infrastructure can be reduced by the civil VTOL system that can be independently operated from the existing airfield and curbside facilities.

Mobility and accessibility. Better mobility and accessibility with point-to-point connections under an on-demand nature of the civil VTOL transport will enhance passenger convenience and experience. Access to remote islands, scarcely populated villages, or natural resource sites might be faster and cheaper than ground transport.

Aircraft utilization. Quick turn-around time of VTOL flights can increase airports' slot capacity and passenger throughputs. 
In the meantime, with the recent robust investment pouring into the autonomous aircraft like Zunum Aero, Volocopter, and Aurora Flight Sciences, there is a higher possibility for civil VTOL aircraft to deploy single or un-crewed configurations.

\section{External Challenges}

A PESTEL analysis is a strategic analysis tool to review on external conditions in business environments or deployment of new technology. In this study, through the PESTEL analysis, potential challenges and countermeasures to deploying the civil VTOL mode were identified and evaluated as shown in Table 2.

The political and regulatory hurdles to overcome are huge, but the venturing of AW609 into real-world scheduled in 2019 to transport passengers by VTOL aircraft is step by step clearing the confusion with the VTOL aircraft system. The efficient propulsion system and a low level of engine noise are the two major technical pre-requisites to deploy a civil VTOL transport into the real world. Both are advancing rapidly, driven by the hybrid-electric propulsion system and battery capacity enhancement (Wang et al., 2015).

Meanwhile, economic feasibility and social acceptance will be a critical area to be overcome by high payload capacity and fully integrated services with an existing air transport system in order to satisfy two most important stakeholders: airlines and passengers. In other words, better accessibility and lower level of fare structure comparing to the conventional air and ground transportation modes will be the basic premise for civil VTOL to successfully inaugurate commercial services to the public. 
Table 2

Challenges and Countermeasures for Civil VTOL Aircraft Operations

\begin{tabular}{|c|c|c|}
\hline Factor & Challenges & Countermeasures \\
\hline Political & $\begin{array}{l}\text { - Lack of global harmonization and } \\
\text { international standard } \\
\text { - First mover's risks }\end{array}$ & $\begin{array}{l}\text { - ICAO SARPs } \\
\text { - Support for mode of public } \\
\text { transportation }\end{array}$ \\
\hline Economical & $\begin{array}{l}\text { - Massive R\&D costs } \\
\text { - Economy of scale (seat capacity) } \\
\text { Initial acquisition and transition } \\
\text { costs: System and infrastructure }\end{array}$ & $\begin{array}{l}\text { - Public-Private Partnership } \\
\text { - Payload increase and single or } \\
\text { zero pilot configuration } \\
\text { - Vertiport at existing airports }\end{array}$ \\
\hline Socio-cultural & $\begin{array}{l}\text { - Safety: debris, collision } \\
\text { - Social acceptance } \\
\text { - Conflict with the existing transport } \\
\text { ecosystem }\end{array}$ & $\begin{array}{l}\text { - Integration with the modernized } \\
\text { CNS/ATM } \\
\text { Public sector initiative as an } \\
\text { urban mobility solution }\end{array}$ \\
\hline Technological & $\begin{array}{l}\text { - Battery capacity and charging time } \\
\text { - Low efficiency during vertical, } \\
\text { transition phase } \\
\text { - Airspace integration }\end{array}$ & $\begin{array}{l}\text { - Battery swapping system } \\
\text { - Hybrid-electric propulsion } \\
\text { - Modernized CNS/ATM } \\
\text { (i.e. NextGen, SESAR) }\end{array}$ \\
\hline Environmental & $\begin{array}{l}\text { - Community noise and emissions } \\
\text { - Wind blaster to ground }\end{array}$ & $\begin{array}{l}\text { - Cruise at mid to high altitude } \\
\text { - Electric propulsion system }\end{array}$ \\
\hline Legal & $\begin{array}{l}\text { - Aircraft \& avionics certification } \\
\text { - Licensing \& slot }\end{array}$ & $\begin{array}{l}\text { - FAA regulatory frameworks } \\
\text { - Part 135: Commuter and On- } \\
\text { demand Operations' transition to } \\
\text { VTOL configuration }\end{array}$ \\
\hline
\end{tabular}

In conclusion, to respond to growing market needs and overcome external challenges, balanced development of three key elements for sustainable civil VTOL system were set as a core of the present scenario-based strategic planning process:

- Enabler: Competitive VTOL technology

- Operation platform: Vertiport infrastructure and procedure

- Differentiator: Enhanced passenger mobility 


\section{Scenario Planning}

\section{The Future State of VTOL System}

Overall gaps were identified through a PESTEL analysis to integrate a civil VTOL system into existing commercial aviation operations. In this section, focusing on technical aspects, Technology Readiness Levels (TRL) measurement as shown in Figure 2 was conducted to quantify the maturity level of each required technology as below. The TRL system helped evaluate new technologies and rated a TRL system with nine technology readiness levels based on current progress (Mankins, 2009).

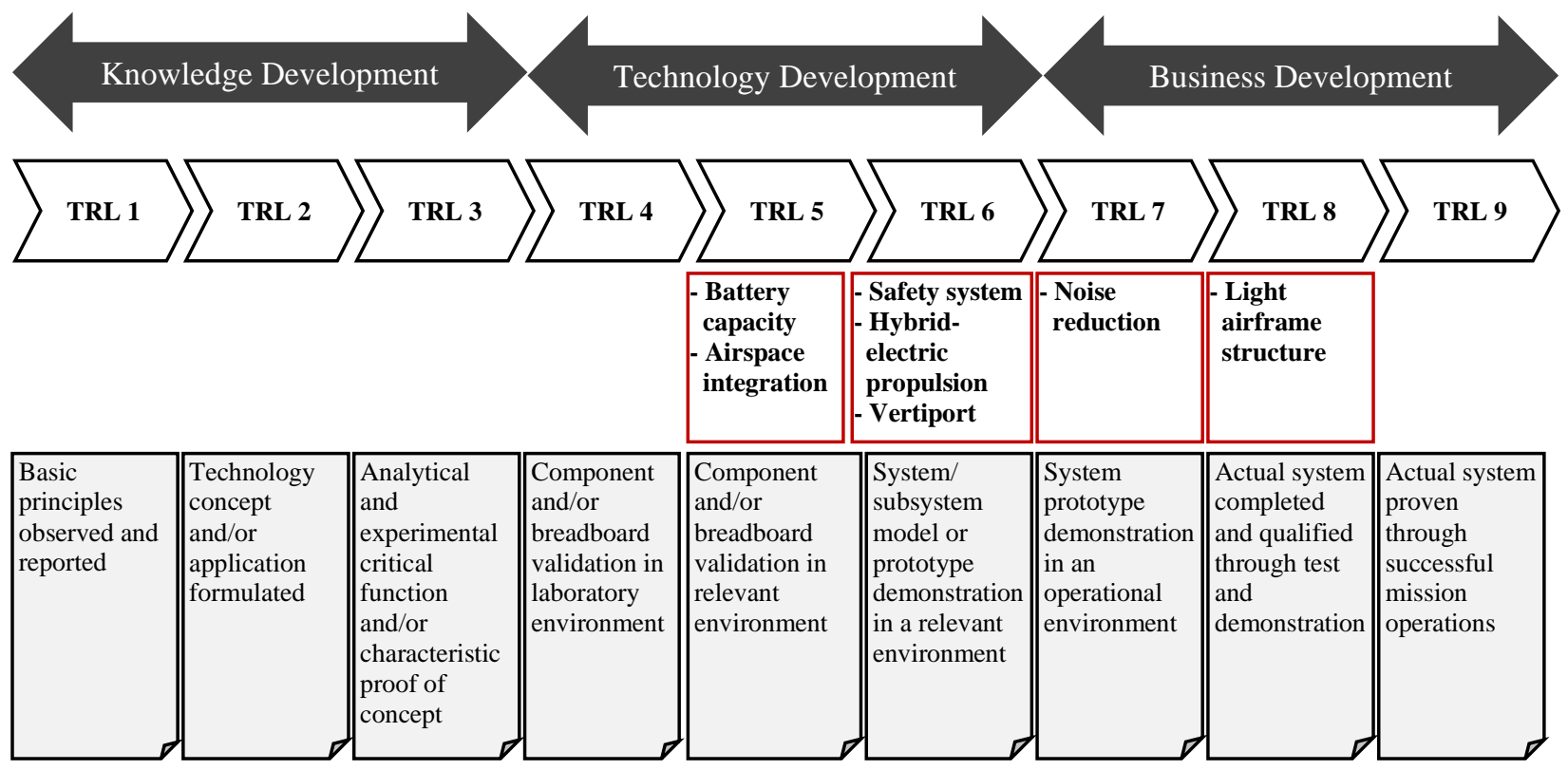

Figure 2. The nine technology readiness levels of the current status of VTOL technology. Adapted from "Technologies progress from TRL 1 through to TRL 9," by J. C. Mankins (1995).

Hybrid-Electric Propulsion. Honeywell and Rolls-Royce are developing a new hybrid propulsion technology and have partnered to develop a 1MW-class hybrid propulsion system for the Aurora Flight Sciences XV-24A, a demonstrator for the DARPA (Trimble, 2017). Judging from the current progress, these technologies would qualify for a readiness level of 6 . 
Battery Capacity. Fuel cell technology continues to mature and the advanced Lipolymer battery is anticipated to be used for aircraft engine propulsion. But high-temperature superconducting materials are at high risk at this stage and expected to be overcome by 2030 (Sinsay et al., 2012; Wang et al., 2015). The battery technology qualifies for a TRL of 5.

Noise Reduction. The AW609 business tiltrotor technology introduced actual noise reduction system and qualified through test and demonstration. From this, we rate the readiness of the technology in air travel at level 7.

Light Airframe Structure. This technology has been developed by airframe manufacturers such as Boeing and Airbus and can be immediately utilized for VTOL aircraft. This corresponds to a technology readiness level of 8 .

Safe Component Systems. While the AW609 business tiltrotor has adopted safe component systems for its commercial flight, scheduled in 2020 for its final certification, the recent fatal crash in October 2015 identified several areas of improvement in its safety system, which qualifies for a readiness level of 6.

Infrastructure (Vertiport). FAA already proposed planning and detail design criteria for vertiport development with five prototype models. So, a prototype is already demonstrated but not yet fully tested for the actual operating system. From a readiness perspective, they qualify for a rating of 6 .

Airspace Integration. Fully integrated model of conventional aircraft and VTOL aircraft has been studied by FAA through the NextGen program but has not yet tested in the real airspace, which qualifies this technology as a rating of 5.

Assumptions from TRL Analysis. The TRL evaluation revealed that energy battery technology and airspace integration will be acting as two critical milestones to commence the 
civil VTOL services. Based on the recent literature on the VTOL technology reviewed in this study, major studies led by NASA on a Civil VTOL Model as shown in Table 1, and NASA's 'Vertical Strategy 2030' (Gorton, 2016), key technical features of civil VTOL aircraft for 2030 were envisioned as below. These technical specifications served as key assumptions for competitiveness analysis and scenario planning:

- Propulsion system: Hybrid-electric propulsion

- Maximum passenger capacity: 120

- Maximum flight range: 500 miles

- Cruise speed: $350 \mathrm{mph}$

- Cruise altitude: $3,000-5,500 \mathrm{ft}$

- Cockpit system: Single pilot supported by the autopilot system

\section{Scenario Development}

The complex interfaces among political, economic, sociological, technological and environmental forces in the air transport system would make it difficult to project a solid scenario with the introduction of the VTOL aircraft as well as an impact on the existing systems. In many cases, due to a strong tendency to maintain the status quo within the existing system, an opportunity to disruptive innovation with new technologies and operating procedures has often been restrained to incremental improvements (Riella \& Teper, 2014). In this regard, three plausible scenarios were constructed as per impact levels on the existing civil air transport system as shown in Table 3 .

Under the Moderate scenario, it is anticipated that the higher level of integration of VTOL into existing air transport system would be required to create synergy in the short-haul transportation market segment. On the other hand, the Aggressive scenario might cause direct 
competition between the civil VTOL mode and conventional air transport system while the

Status Quo scenario would not actively interfere with current air transport system.

Table 3

Scenario Planning with Three Potential Anticipating Models

\begin{tabular}{ll}
\hline Scenario & \\
\hline & Description \\
Status Quo & Limited interaction with existing air transport system. \\
& VTOL as an intra-city mode of transportation and supplement to a helicopter \\
& - No significant impact on existing air transport system. \\
\hline & - Integrated operation of VTOL aircraft with a conventional aircraft system. \\
Moderate & - VTOL serving inter-city public transportation systems. \\
& - Airports provide passengers with on-site transfer between long-haul/mass air \\
& transport by conventional aircraft and short-haul traffic by VTOL. \\
& - Disruption of short-haul air network system by advanced VTOL system. \\
& - Maximum utilization of VTOL both for inter- and intra-city transportation and \\
& competition with conventional airline services. \\
Aggressive & Development of dedicated vertiports at urban/suburban destinations like bus \\
& terminals.
\end{tabular}

\section{Scenario Assessment}

Because compatibility and synergetic interface with the current air transport system will play a crucial role in the sustainable development of a civil VTOL system, eight goals for supporting the sustainable air transport system were chosen and set as assessment criteria divided into three segments to evaluate the proposed three scenarios.

1) Enabler: Competitive VTOL Technology

- Goal 1: Enhancing safety performance. Safety issues of VTOL aircraft have continuously been raised. V-22 and Harrier family have shown higher accident rate among all military aircraft (Zhou, Zhao, \& Liu, 2020). The hybrid propulsion and the transition technology 
between vertical take-off and landing and cruise mode of flight should resolve the flight safety issues.

- Goal 2: Affordable research and development (R\&D) costs. The R\&D cost for VTOL technology is one of the key points for introducing a new type of aerial vehicles. The R\&D budget for the V-22 had been initially planned for $\$ 2.5$ billion in 1986 , which increased to approximately $\$ 30$ billion in 1988 (Zhou, Zhao, \& Liu, 2020).

- Goal 3: Reduction of community noise impact. While conventional airplanes still create a significant noise footprint over 20 square miles for takeoff and landing, a VTOL flight procedure is expected to dramatically reduce the noise impact zone to just 3000 feet radius (Gorton, 2016). Therefore, active deployment of VTOL procedure will vastly reduce community noise pollution.

- Goal 4: Competitive operation and maintenance costs. VTOL is efficient when it cruises but consumes substantial energy for takeoff and climb (Kasliwal et al., 2019). Also, because lift engines serve as deadweight while cruising, more weight and distance it needs to transport, which means more fuel needs to be consumed.

2) Operation Platform: Vertiport infrastructure and procedure

- Goal 5: Increase of airport throughput. The civil VTOL transport mode is expected to increase traffic throughput at congested airports by expanding capacity of existing infrastructure with minimum investment.

- Goal 6: Affordable infrastructure transition costs. Minimize development and transition cost for developing vertiport infrastructure to deploy the VTOL system, which is a financial burden to airport operators and airlines.

3) Differentiator: Enhanced passenger mobility 
- Goal 7: Enhanced urban mobility (time and cost). Reducing time and cost for passengers by introducing urban air mobility between population centers and serving airports by using the on-demand mode of air transportation.

- Goal 8: Enhanced urban mobility (accessibility). Increasing accessibility to remote and non-airport locations and providing passengers with seamless travel experience.

The impact of each scenario model on the current air transport system, in terms of the aforementioned nine goals, was assessed and shown in the matrix form in Table 4. Among the proposed three plausible scenarios, the Moderate scenario is evaluated as the most feasible model to support the current air transport industry to maintain sustainable growth in the future.

Table 4

Assessment Matrix of Proposed Scenarios

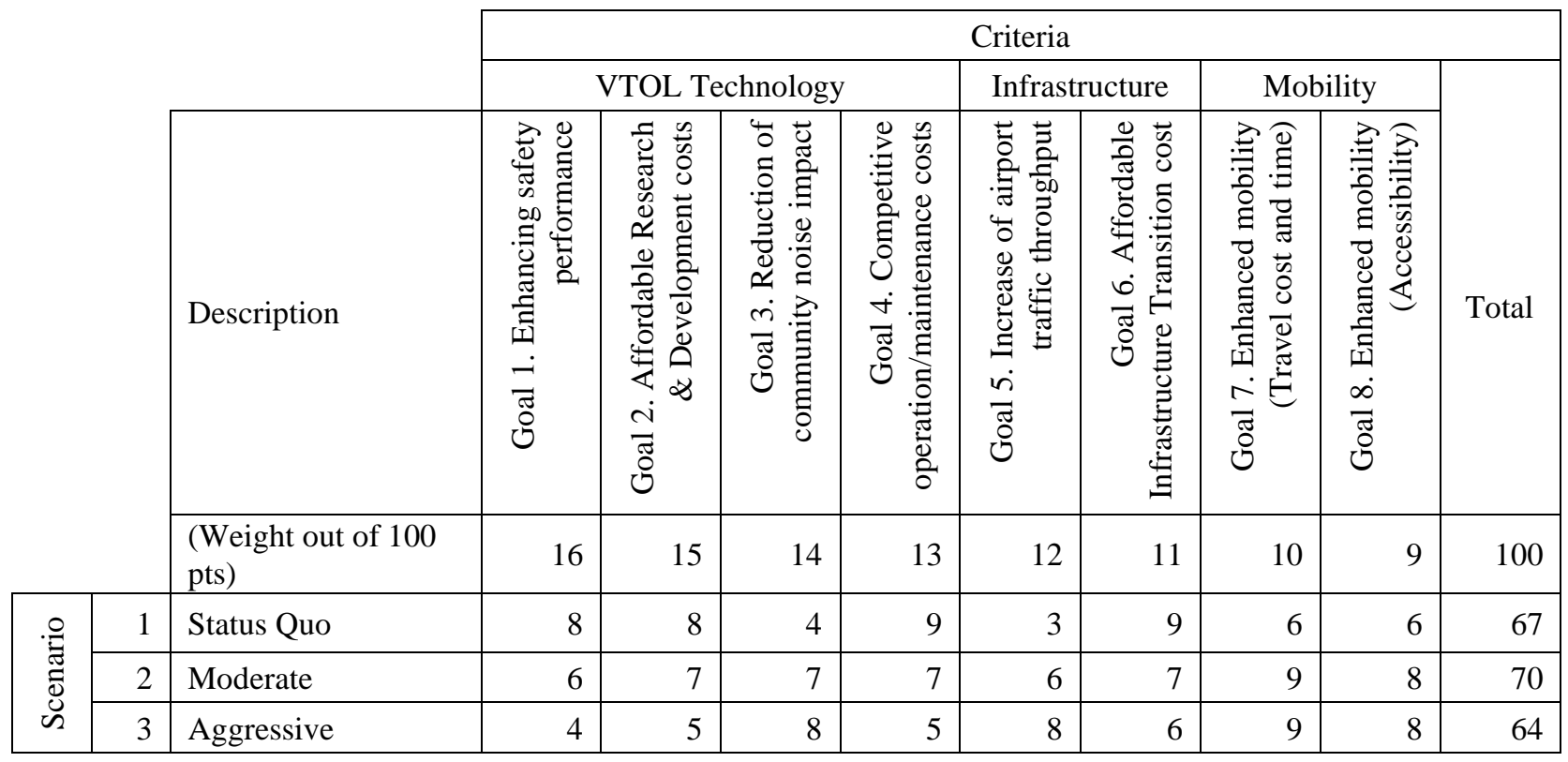

Note. Assessment of scenario was made based on the Option Matrix Tool (OMT) (Enz \& Thompson, 2013). The score of each criteria item was ranged between 1 (low rated) and 10 (high rated). 


\section{Strategy Development for Moderate Scenario}

\section{Strategic Approach to Civil VTOL Deployment}

The success of the Moderate scenario will largely depend on the compatibility and synergetic development of VTOL technologies with the existing infrastructure. With this consideration, three key elements for sustainable civil VTOL system as identified through the PESTEL analysis were revisited to develop a strategic plan for the Moderate scenario.

Competitive VTOL technology. Although it has been more than four decades since the VTOL aircraft technology was first introduced in the industry, lack of competitiveness comparing to ground transportation has hindered the benefit of the VTOL technology. The development of autonomous configurations for civil VTOL will become an avenue towards meeting the future travel demand for high-mobility and integrative operations with other transit transport modes. Besides three basic technical requirements—efficient propulsion, quiet vehicles, and safe operations - competitive advantage will be gained through the convergence of VTOL and autonomous technologies.

Infrastructure and procedure. The conceptual vertiport layout illustrated in Figure 3 was presented to inspire future planning efforts by airport planners. The proposed concept includes simultaneous non-interfering operations between conventional aircraft and VTOL aircraft, co-locating vertiports at the airport for maximum utilization of existing facilities and passenger convenience while minimizing interface between conventional aircraft by avoiding the existing runway system. Because of large gross-weight VTOL aircraft, highly induced velocities and wind blast from the aircraft, the physical operations of VTOL aircraft shall be segregated from ground infrastructures like terminals and aero-bridges. The VTOL aircraft turn-around 
time and interface with existing airport operations can be significantly reduced by adopting an approach with an automated VTOL aircraft flowing system proposed by Trimble in 2018.

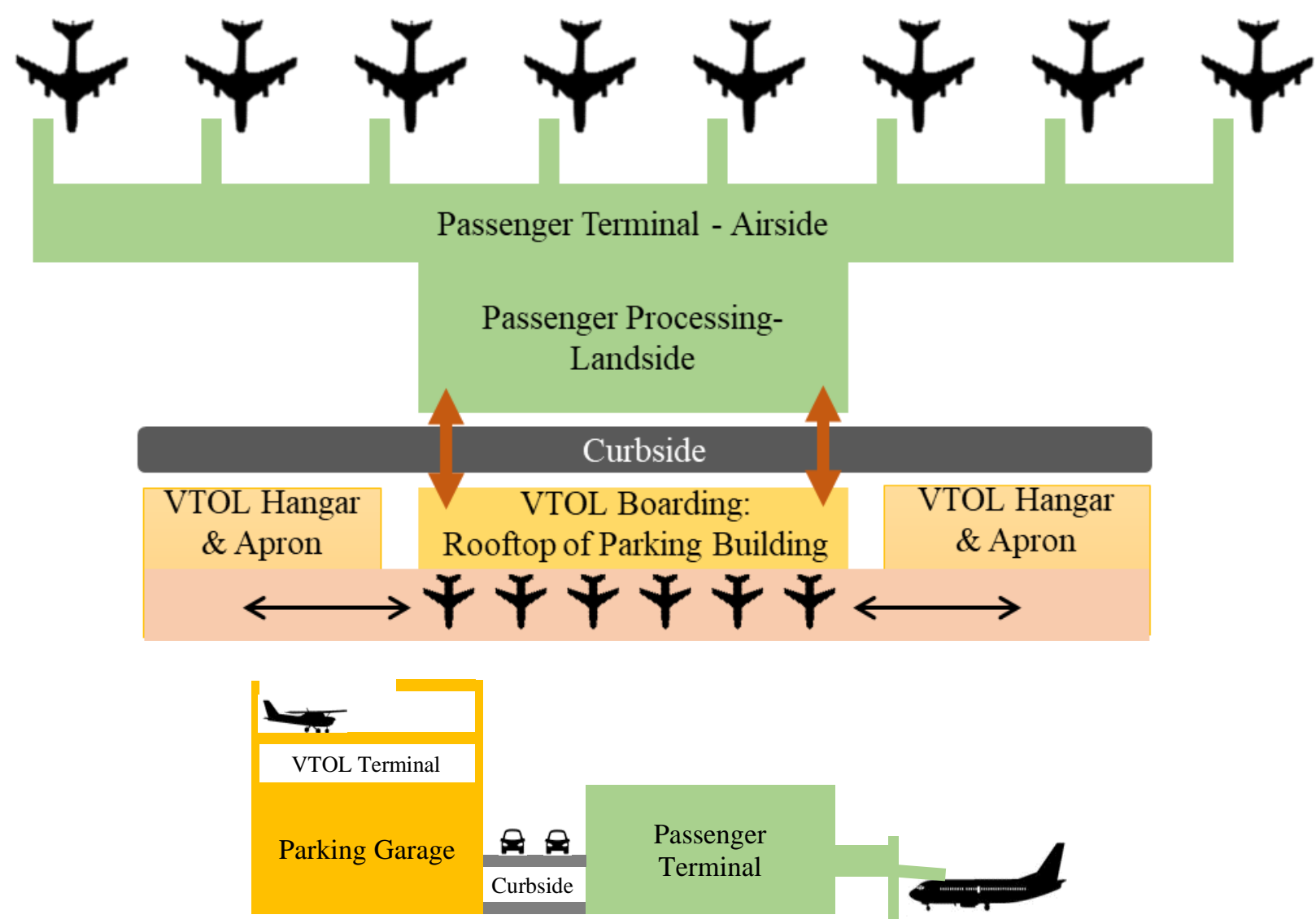

Figure 3. Airport - Vertiport configuration conceptual layout. Not to scale.

Enhanced passenger mobility. Due to the technical challenges related to airspace integration of VTOL with conventional aircraft such as sequencing, spacing, and scheduling, establishing dedicated airspaces or air corridors with published procedures only to VTOL aircraft is likely to expedite enabling civil VTOL operations and ensure more controlled operations than mixing with traditional VFR/IFR aircraft.

However, by maximizing the values and benefits of the VTOL flights, the integrated operation of VTOL aircraft into the air transportation system will support the industry to 
strengthen its competitiveness and expand its role to integrate intra- and inter-city connectivity. For instance, metropolitan cities having multiple airports and population centers like Los Angeles, San Francisco, New York, and Orlando are expected to benefit from the civil VTOL system by improving the efficiency of the urban transportation network as shown in Figure 4. Passengers will have multiple choices among different modes of transportation to move between airports, downtown, major tourist attractions and other adjacent cities. The enhancement of transfer flow and mobility of passengers and goods at airports will generate spin-off commercial opportunities, which will expand roles of airports into airport cities.

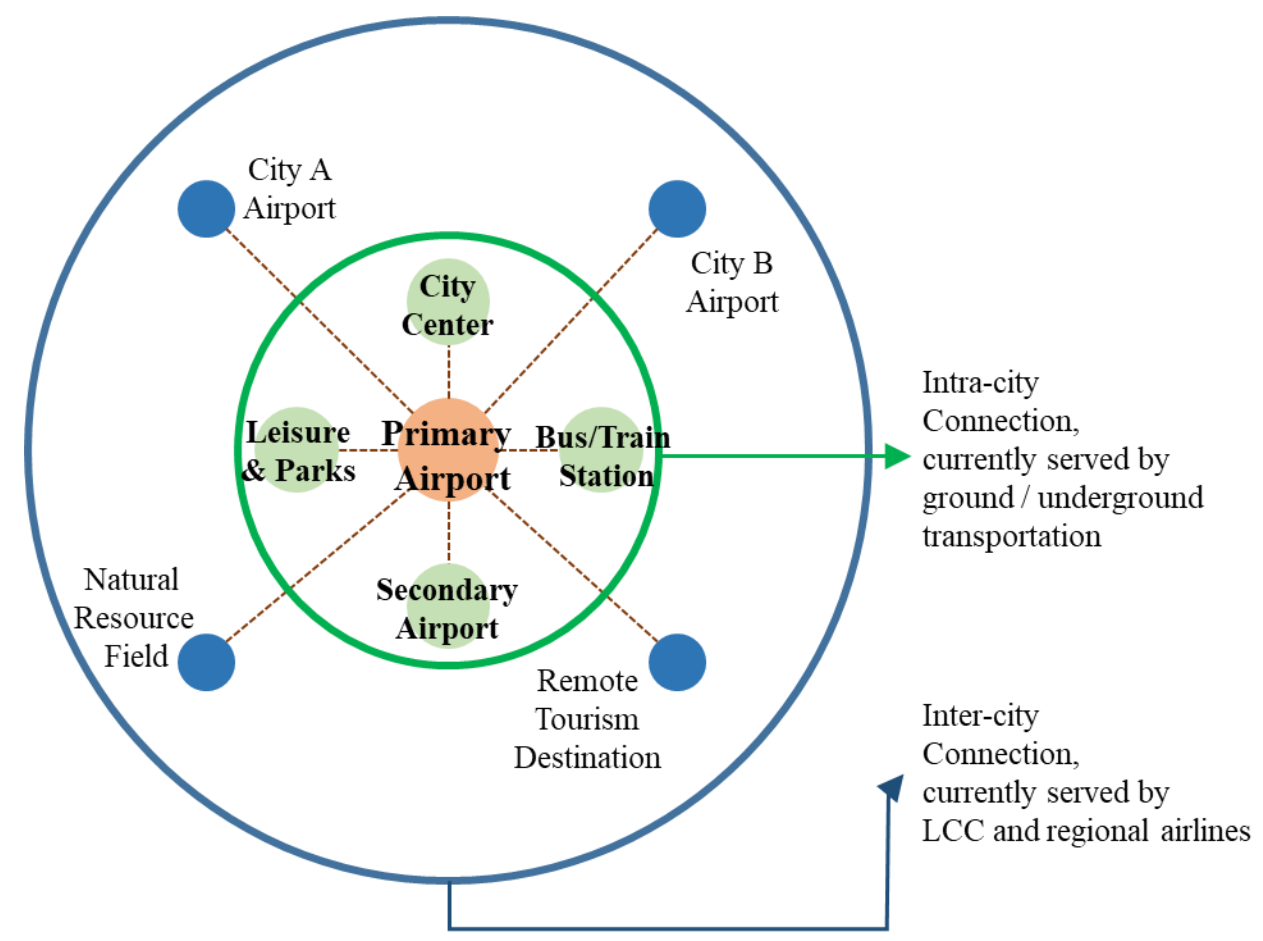

Figure 4. Civil VTOL point to point integrative network diagram.

\section{Future Roadmap}

Due to the integrative nature of the air transport system, many civil VTOL component systems are mutually dependent on existing systems. For instance, a UAS traffic management 
(UTM) system for UAS operating at low altitudes and integration of UAS into NextGen automation system can provide services appropriate for the autonomous VTOL flight. In consideration of the dynamics among related stakeholders and required system elements, the roadmap for full-fledged VTOL flight operations up to 2040 was projected as shown in Table 5. In the near-term, VTOL aircraft carrying up to nine passengers is expected to commence commercial operations for intra-city transport as a part of a public transport system. Under public sector leadership, regulatory frameworks and operational procedure shall be established.

In the mid-term, along with increased passenger and cruising capacity, economic feasibility will be enhanced, which can attract the private sector's interest and investment. In the long-term, VTOL will be able to accommodate significant short-haul market share and help improve urban mobility system integrated with the variety of smart-city solutions.

Table 5

Civil VTOL Aircraft Long-term Roadmap to 2040

\begin{tabular}{|c|c|c|c|}
\hline & Near-term (- 2025) & Mid-term (2026-2030) & Long-term (2031-2040) \\
\hline Stage & $\begin{array}{l}\text { Launch with smaller } \\
\text { VTOL systems }\end{array}$ & $\begin{array}{l}\text { The advent of civil } \\
\text { VTOL market }\end{array}$ & $\begin{array}{l}\text { The maturity of civil } \\
\text { VTOL industry }\end{array}$ \\
\hline Leadership & Public sector & $\begin{array}{l}\text { Public-Private } \\
\text { Partnership }\end{array}$ & Private sector \\
\hline Payload Capacity & 9 seats & 30 seats & 120 seats \\
\hline $\begin{array}{l}\text { Enabler: } \\
\text { Sustainable VTOL } \\
\text { Technology }\end{array}$ & $\begin{array}{l}\text { Increase capability of } \\
\text { vertical lift } \\
\text { configuration }\end{array}$ & $\begin{array}{l}\text { Hybrid-electric } \\
\text { propulsion / battery } \\
\text { solution }\end{array}$ & $\begin{array}{l}\text { Autonomous system } \\
\text { deployment }\end{array}$ \\
\hline $\begin{array}{l}\text { Platform: } \\
\text { Vertiport } \\
\text { infrastructure }\end{array}$ & $\begin{array}{l}\text { Pilot vertiport sites } \\
\text { allocation and setting } \\
\text { design standards }\end{array}$ & $\begin{array}{l}\text { Integrated operation of } \\
\text { vertiport \& airport }\end{array}$ & $\begin{array}{l}\text { Expanded roles as an } \\
\text { urban mobility system }\end{array}$ \\
\hline \multicolumn{4}{|l|}{ Differentiator: } \\
\hline $\begin{array}{l}\text { Integration of VTOL } \\
\text { into the existing } \\
\text { transport system }\end{array}$ & $\begin{array}{l}\text { VTOL operation } \\
\text { procedures and manuals }\end{array}$ & $\begin{array}{l}\text { Integration with } \\
\text { NextGen System }\end{array}$ & Autonomous Operations \\
\hline
\end{tabular}




\section{Discussion: Implication and Path Forward}

Successful deployment of the civil VTOL aircraft will call for a system-wide transformation of the air transport industry_including communication, physical infrastructure, related key technology advancement, and procedural changes. As a basis for developing proper methods and models that encompass the political, economic, social, and technical complexity and dynamics of the air transport industry, it will be necessary for regulators, manufacturers, operators, and municipalities to organize a joint workforce or formal steering committee to endeavor collaborative efforts not only to address outstanding issues with the air transport industry but also to maximize benefits for expanded areas such as urban planning and tourism development. Key agenda in the context of civil VTOL deployment were proposed as below.

Government. At the initial stage, government's role will not be limited as a regulator but expended to as a program leader, and sponsor, that takes initiative to facilitate the VTOL transport mode into the real life, which needs to be supported by the national transportation master plan.

Regulation / ATC. Procedures for vertical take-off and landing procedures of the VTOL aircraft will be similar to helipad operations at airports and city centers but must also consider maximum take-off weights and wind blast during vertical take-off and landing.

Airport Infrastructure. Development or alteration of the landside complex into the multi-modal transportation center integrating passenger processors, vertiport, and ground transportation will have strategic potentials to enhance passenger throughput and commercial performance of the airport. Fees and charge schemes need to be restructured.

Airlines. In a long-term, business impact on the airline industry will be vast and restructuring of a short-haul air transport network system is unavoidable. There will be a 
possibility of new business models and new entities, as the industry experienced with the advent of LCCs.

Urban / Suburban. Development of vertiports in the urban population centers will increase the benefits of the VTOL technology. Underdeveloped suburban areas with tourism potential will also have the opportunity to grow as a tourism destination.

Tourism and Hospitality. While airports will explore the potentials of becoming an integrative transportation and tourism hub for passengers, its importance to the tourism industry will be increasing. Joint efforts between the tourism and hospitality industry and airport operators will find opportunities to expand economic benefit to improve passenger mobility to existing tourism sites as well as develop new tourism destinations.

\section{Conclusions and Recommendations}

This study aimed to envision a feasible scenario for an integrative development of civil VTOL aircraft within the existing air transport system for a 20+-year timeline and propose a strategic development framework. Despite growing market needs and potential benefits, many external challenges and regulatory gaps were identified through PESTEL analysis to integrate civil VTOL aircraft into the existing commercial aviation system.

Among the three presented plausible scenarios, this study suggests that the deployment of the future civil VTOL system, under the Moderate scenario, will be the most appropriate way to relieve current infrastructure and airspace congestion issues as well as provide passengers with enhanced mobility for the inter- and intra-city transport. The Moderate scenario can also benefit aviation stakeholders to utilize existing airport infrastructure for accommodating civil VTOL aircraft with modest alterations, which will leverage to achieve a near-term capability with minimizing development costs and creating a competitive advantage over other ground transport 
systems such as railway and automobiles. However, upgrading existing air transport infrastructure and operational procedures with the civil VTOL technology will require complex reconfiguration processes as well as collaborative efforts among all related stakeholders.

Finally, integrative development of the civil VTOL system within the existing conventional air transport system would largely impact both on existing air and ground transport networks. In this regard, to evaluate the impact and benefits of the civil VTOL system on the existing transport system and develop an optimum solution, regional traffic network model with actual metropolitan areas needs to be constructed and simulated. For instance, Greater Orlando Metropolitan is expected to entertain the significant benefits from the civil VTOL system as it could improve efficiency of the overall transportation network system due to a majority of short haul air traffic demand, current multi-airport system, and high demand for urban mobility to connect multiple population centers and major tourist attractions. 


\section{References}

Airport Council International (ACI). (2017). ACI update: Preliminary 2016 world airport traffic rankings. Journal of Airport Management, 11(3), 327-331.

Albers, J. A., \& Zuk, J. (1987). Civil applications of high speed rotorcraft and powered lift aircraft configurations. (NASA Technical Memorandum 100035). Retrieved from https://ntrs.nasa.gov/archive/nasa/casi.ntrs.nasa.gov/19880002261.pdf

Chung, W. W., Linse, D., Salvano D., Trept, T., Wood, T., Gao, H., . . Cheng, V. (2011). Modeling high-speed civil tiltrotor transports in the next generation airspace (NASA CR 2011-215960). Retrieved from https://rotorcraft.arc.nasa.gov/CR-2011215960_10_26_11_Hi_Res.pdf

Clarke, C. (2015, March 10). Everything you need to know about the first civilian tilt rotor aircraft. Jalopnik. Retrieved from https://jalopnik.com/everything-you-need-to-knowabout-the-first-civilian-ti-1689618757

Enz, C. A., \& Thompson, G. (2013). The Options Matrix Tool (OMT): A strategic decisionmaking tool to evaluate decision alternatives. Cornell Hospitality Tools, 4(1), 6-11.

Eurocontrol. (2017). Delays to air transport in Europe (CODA Digest: Technical Report). Retrieved from https://www.eurocontrol.int/articles/coda-publications

Federal Aviation Administration (FAA). (2015). Airport capacity constraints and needs in the national airspace system (Federal Information \& News Dispatch). Washington, DC. Retrieved from https://www.faa.gov/airports/planning_capacity/media/FACT3-AirportCapacity-Needs-in-the-NAS.pdf 
Fife, W., \& McNerney, M. T. (2000). A look into the future of airport planning, design, and construction by analyzing current issues. Paper presented at the Transportation Research Board, Washington, DC. Retrieved from http://onlinepubs.trb.org/onlinepubs/millennium/00002.pdf

German, B., Trani, T., Smith, J., Goodrich, K., Moore, M. D., Fredericks, B., . . Viken, J. (2013). High speed mobility through on-demand aviation. Retrieved from https://ntrs.nasa.gov/search.jsp?R=20140002448

Goncalves, S. (2016). DARPA's experimental VTOL plane looks like the Osprey of tomorrow. $E C N$, Retrieved from http://search.proquest.com.ezproxy.libproxy.db.erau.edu/docview $/ 1771329068$ ?accountid=27203

Gorton, S. A. (2016). NASA vertical lift strategic direction. Retrieved from https://rotorcraft.arc.nasa.gov/02\%20NASA\%202016\%20University\%20Day\%20for\%20 VLRCOE\%20final.pdf

Kasliwal, A., Furbush, N. J., Gawron, J. H., McBride, J. R., Wallington, T. J., De Kleine, R. D., ... Keoleian, G. A. (2019). Role of flying cars in sustainable mobility. Nature Communications, 10(1), 1555-9. https://doi.org/10.1038/s41467-019-09426-0

Lindsey, J., Young, R., Rinehart, D., Chung, W. W., Salvano, D., \& Cheng, V. (2012). An assessment of civil tiltrotor concept of operations in the next generation air transportation system. (NASA Technical Report). Retrieved from https://ntrs.nasa.gov/archive/nasa/casi.ntrs.nasa.gov/20120015068.pdf

Mankins, J. C. (1995, April). Technology readiness levels: A white paper. Advanced Concepts Office, NASA. 
Mankins, J. C. (2009). Technology readiness assessments: A retrospective. Acta Astronautica, 65(9-10), 1216-1223. https://doi.org/10.1016/j.actaastro.2009.03.058

Moore, M. D., \& Goodrich, K. H. (2013, August). High-speed mobility through on-demand aviation. Paper presented at Aviation Technology, Integration, and Operations (ATIO) Conference, Los Angeles, CA. https://doi.org/10.2514/6.2013-4373

Mueller, E. R., Kopardekar, P. H., \& Goodrich, K. H. (2017, June). Enabling airspace integration for high-density on-demand mobility operations. Proceedings of the 17th AIAA Aviation Technology, Integration, and Operations Conference, Denver, CO. https://doi.org/10.2514/6.2017-3086

Organisation for Economic Co-operation and Development (OECD). (2014). Expanding airport capacity in large urban areas. Paris, France: OECD Publishing.

Ozdemir, U., Aktas, Y. O., Vuruskan, A., Dereli, Y., Tarhan, A. F., Demirbag, K., . . Inalhan, G. (2014). Design of a commercial hybrid VTOL UAV system. Journal of Intelligent \& Robotic Systems, 74(1), 371-393. https://doi.org/10.1007/s10846-013-9900-0

Patterson, M., German, B., Barraclough, J., Moore, M. D., Smith, J., Trani, T., \& Fredericks, B. (2013, August). High speed mobility through on-demand aviation. Paper presented at the AIAA Aviation Technology, Integration, and Operations (ATIO) Conference, Los Angeles, CA.

Peisen, D., \& Ferguson, S. (1996). Vertiport design characteristics for advanced rotorcraft technology (SAE Technical Paper 965521). https://doi.org/10.4271/965521

Perry, D. (2016). HELI-EXPO: Return to flight edges closer for AW609 tiltrotor. Reed Business Information Ltd. 
Riella, G., \& Teper, R. (2014). Probabilistic dominance and status quo bias. Games and Economic Behavior, 87, 288-304. https://doi.org/10.1016/j.geb.2014.04.010

Sinsay, J., Alonso, J., Kontinos, D., Melton, J., \& Grabbe, S. (2012, September). Air vehicle design and technology considerations for an electric VTOL metro-regional public transportation system. Paper presented at 12th AIAA Aviation Technology, Integration, and Operations (ATIO) Conference and 14th AIAA/ISSMO Multidisciplinary Analysis and Optimization Conference, Indianapolis, IN. https://doi.org/10.2514/6.2012-5404

Sternberg, A., Soares, J., Carvalho, D., \& Ogasawara, E. (2017). A Review on Flight Delay Prediction. Retrieved from https://arxiv.org/abs/1703.06118

Trimble, S. (2017). Sparking off a revolution. London, England: Reed Business Information UK.

Trimble, S. (2018). Volocopter explains urban mobility concept in new video. Reed Business Information Ltd.

Wang, B., Hou, Z., Guo, Z., \& Gao, X. (2015). Space range estimate for battery-powered vertical take-off and landing aircraft. Journal of Central South University, 22(9), 3338-3346. https://doi.org/10.1007/s11771-015-2874-2

Warwick, G. (2014). Personal Air Travel. Cleveland, OH: Penton Media, Inc.

Wood, T. (2012). One engine inoperative (OEI) and autorotation for heavy lift rotorcraft systems. (NASA Technical Report). Retrieved from https://rotorcraft.arc.nasa.gov/Publications/files/Wood_CR_2012_216038.pdf

Xue, M. (2006). Real-time terminal area trajectory planning for runway independent aircraft. Retrieved from http://search.proquest.com.ezproxy.libproxy.db.erau.edu/docview /305301236?accountid=27203 
Young, L. A, Chung, W., Paris, A., Salvano, D., Young, R., Gao, H., .. . Wright, K. (2011, September). Civil tiltrotor aircraft operations. Paper presented at the 11th AIAA Aviation Technology, Integration, and Operations (ATIO) Conference, Virginia Beach, VA. https://doi.org/10.2514/6.2011-6898

Young, L. A., \& Rajagopalan, G. (2013, January). Simulated rotor wake interactions resulting from civil tiltrotor aircraft operations near vertiport terminals. Paper presented at $51^{\text {st }}$ AIAA Aerospace Sciences Meeting, Grapevine, TX. https://doi.org/10.2514/6.2013801Zhou, Y., Zhao, H., \& Liu, Y. (2020). An evaluative review of the VTOL technologies for unmanned and manned aerial vehicles. Computer Communications, 149, 356-369. https://doi.org/10.1016/j.comcom.2019.10.016 